\title{
The Construct of 'Respect' in Teacher-Student Relationships: Exploring Dimensions of Ethics of Care and Sustainable Development
}

\author{
Canute S. Thompson, PhD. \\ Lecturer \\ School of Education \\ Mona Campus of The University of the West Indies
}

\begin{abstract}
This study examines the construct of respect, its manifestations in teacher-student relationships, and it relationship to ethics of care and sustainable development. The study found that students place a high premium on being respected by their teachers and measure expressions of respect chiefly through the attention received through listening. Students' perspectives on the quality of the schools' leadership and the teaching and learning environment were found to be shaped by their assessments of the degree to which they feel respected. In a number bivariate correlations, the study found strong, positive correlations between the variable 'listening' and other variables that characterize the teacher-student relationship, in particular respect for teachers and principals and comfort with the teaching and learning environment.

The study makes the case that the act of showing respect is a critical component of the ethics of care and sustainable development. The study recommends that one strategy that teachers and educational administrators should adopt in seeking to strengthen teacher-student relationships, exert positive influence on students' behaviours and academic performance, and thus ensure the sustainability of healthy social environments is to invest in the creation of organizational cultures and administrative systems and processes that create the avenues through which respect for students can be demonstrably seen.
\end{abstract}

\section{Introduction}

The job of leadership involves inspiring others to share a vision and follow in the direction the leader is taking towards that vision. The Centre for Visionary Leadership asserts that the most effective visionary leaders are responsive to the real needs of people. A leader's capacity to be responsive to the needs of others depends on the extent to which the leader has developed and is exercising the discipline of respect, which is often expressed through active listening. In effect, therefore, a leader's capacity to inspire others to share a vision depends not only on his or her capacity to communicate, but equally on his or her ability to listen (Covey, 2000). There are many reasons leaders listen to those they seek to lead. Two of the most important reasons are (a) to demonstrate respect for the views and perspectives of others, and (b) to ensure that the organization benefits from the wisdom and insights of others (Thompson, 2015). 
This focus of this study was triggered by data conducted from a wider study that sought to explore students' perceptions and expectations of leaders in a postmodern era. The findings of the study revealed that the variable respect accounted for a significant percentage of the variation in the data. Based on those findings it became evident that a further exploration of what respect means should be the subject of further exploration. This paper represents that further exploration.

In undertaking the further exploration two new constructs emerged as prisms through which respect should be understood. The two constructs are "ethics of care" and "sustainable development". The exploration of these concepts, within the context of students' relationships with their teachers, would be valuable only to the extent that they positively impact performance, the overall quality of teacher-student and student-student relationships, as well as the extent to which the teaching and learning environment prepares students for functioning in the world after school.

Ethics of care is a theory that promotes a pragmatic and practical mode of engagement, centered on the notion of interdependence and takes account of the indispensability of community and recognizes that some people are more vulnerable than others and thus seeks to afford them extra consideration (Gillian, 1982). Unlike other philosophical principles that hold that there are absolutes, ethic of care asserts that there is no universal truth. In this regard ethic of care is particularized, contextualized, and evolutionary as it seeks to promote the specific needs and interests of the vulnerable communities (Noddings, 1984). Students represent the less powerful constituency within the school community and allowing others to have a voice is one of the most potent expressions of power-sharing and therefore, also, an expression of the ethics of care. Thus the culture of listening in a school, which is founded on allowing others to have a voice, forms the framework not only of an ethos of ethics of care but also, a contributor to improved student discipline and academic performance.

The quality of relationships between and among people who share common interests, spaces, destinies, and relationships, critical elements of the issue of sustainable development (Howarth, 2012). Fundamental to the preservation of the common interests, spaces, and relationships that people share, are mutually respectful relationships. This assertion is applicable to all contexts in which people share common interests and destinies, and therefore applicable to the teaching and learning environment of schools. A central component of respect is listening and as Covey (2000) argues, listening plays a role in all effective leadership. Thompson (2009) found that the degree to which students perceive respect in their learning environment, which respect is manifested in the willingness of their leaders to listen has implications for the effectiveness of teaching and learning. It is against the background of the established position that listening lies at the root of a host of positive outcomes of teacher-student relationships that this study seeks to explore Jamaican students' perspectives on listening and its relationship to their assessment of the quality of the leadership of their schools. The assumption this study makes, based on available evidence from a qualitative study, is that positive teacher-student relationships constitute an important element among the factors that contribute to improved student discipline, student performance, and sustainable development. 
Statement of the Problem. The 2015 Report of Jamaica's National Education Inspectorate (NEI) shows that students' attainment in English and Mathematics was below the targets set by the Ministry of Education in $78 \%$ of the 953 schools inspected. Students' progress was rated as unsatisfactory in 51\% of schools, and teaching in support of students' learning was unsatisfactory in $44 \%$ of schools. Overall, $55 \%$ of the 953 schools were rated as ineffective.

Dunkley (2013), reporting on a Ministry paper tabled by the Ministry of Education in Parliament in May 2013, stated that there were 915 fights, 160 robberies and three murders reported in Jamaican schools in the 2012/13 academic year. In addition, 1,288 weapons were seized, including 431 knives and 486 pairs of scissors. School resources officers arrested 201 students, cautioned 2,361 and monitored 1,109. According to the report, illegal substances were seized on 164 occasions. A 2015 Child Month report showed that between the academic years 2009-10 and 2012-13 there were 4,973 expulsions and some and tens of thousands of suspensions.

The foregoing situation depicts an education system in crisis. The consequences of failing to deal effectively with the problems described above include, but are not limited to

- insufficient numbers of adequately trained persons to assume leadership roles in society;

- high school graduates who are not capable of acquiring skills that are needed to improve living conditions in society;

- the risk that with less than marketable skills, students enter adulthood being overly dependent on the state for support and thus pose risks to the environment and efforts at sustainable development.

The solutions to the problems of academic underachievement, inappropriate modes of engagement between teachers and students, student indiscipline, and unsustainable development practices are multidimensional and complex. This paper does not attempt to explore a range solutions related to each of them but seeks to explore the perspectives of students concerning their perceptions of their teachers' and principals' display of respect towards them and their assessment of quality of the leadership and learning environment that the display of respect conveys. The paper seeks further to examine the implications of the mode of teacher-student engagement for ethics of care and sustainable development.

The quality of leadership is an important part of the overall quality of teaching and learning. The quality of teaching and learning has been identified by Leithwood et al. (2004) as the single greatest factor in determining educational outcomes. The larger question that this paper thus seeks to explore is whether students' perspectives of their teachers' display of respect provide clues concerning the fundamental components of the quality of teaching and learning which, according the Starratt (2005), is related to the ethics of care and, as a principle of how community is maintained according to Agenda 21, sustainable development. 
Objectives of the Study and Research Questions. Thus the objectives of this paper are:

(a) to ascertain students' perspectives on the role of respect in their relationships with their teachers;

(b) to understand whether there is a relationship between students' experience of being respected and their assessment of the quality of leadership and learning environments of their schools;

(c) to explore the relationship between students' experience and display of respect and the issue of sustainable development.

Based on the foregoing objectives, the research seeks to answer the following questions:

1. What are students' assessments of their teachers' and principals' demonstrations of respect towards them and do these assessments influence the respect they have for their teachers and principals?

2. Is there a relationship between students' assessment of their teachers' and principals' demonstration of respect their views on the quality of their schools' leadership and learning environment?

3. Are students' assessments of the extent to which their teachers and principals show them respect affected by variables such as gender, school type, and school location?

4. Is there support in the scientific literature for characterizing teachers' and principals' display of in respect being related to the ethics of care and sustainable development?

Significance and Scope of the Study. This study is significant for at least three reasons, namely:

(1) it seeks to address an exceedingly important area of teacher-student relationships - one that has potentially major implications for the quality of teaching and learning;

(2) it offers new insights on the relationship between on an important element of teachers' behavior (respect) and other critical variables that inform students' relationship with their learning environment;

(3) it opens new perspectives on the question of the type and quality of leadership that students expect from their teachers and principals;

(4) it opens up a new dimension of a discourse on the issues of ethics and sustainable development.

\section{Literature Review}

Defining Respect. The Stanford Encyclopedia (2014) defines respect as a responsive relation which is expressed in various ways including attention, deference, acknowledgment, valuing, and behaviour. The English word respect is derived from the respicere, which means "to look back at" or "to look again". The Stanford Encyclopedia further notes that respect is a particular mode of apprehending the object, and explains that the person who respects something pays attention to it and perceives it differently from someone who does not. It is therefore instructive that the synonyms for respect are words such regard, which means to "to watch out for" and consideration, which means "to examine carefully" or "paying close attention to".

Respect requires paying close attention and involves other behaviours such as deference and acknowledgement, as well as a philosophical orientation of valuing another's point of view. 
Relying on the ethical theory of Immanuel Kant, Wood (1999) suggests that when one respects another, one is not prone to be oblivious or indifferent to that person, or to ignore or quickly dismiss that person, neglecting or disregarding that person, and argues that it is morally wrong to express disrespect or contempt for persons by not valuing them as ends in themselves.

The importance of respect, as part of the process of leadership, is not confined to the world of business and to adults. It is equally important when leading schools and relating to students. Kohn (1996) contends that children are more likely to be respectful when important adults in their lives respect them; a view later echoed by Boynton and Boynton (2005) who note that people are more apt to go out of their way to please a boss who they believe values them as individuals and treats them with dignity and respect. According the Boynton and Boynton, students have the same feelings as adults do. They thus conclude that in order to foster positive teacher-student relations and improve student discipline teachers should seek to show respect to students. Thus if respect has positive effects on teacher-student behavior then the absence of respect may be deemed to be a contributor to negative student-teacher relationships and negative attitudes of students towards school and school authorities, although the negative attitudes of students towards school and school authorities result from a variety of factors.

Ethics of Care. Burton and Dunn (1996) assert that 'ethics of care' refer to ideas concerning both nature and morality. They suggest that the construct stands in contrast to ethical theories such as Kantian deontology and utilitarianism which are principles to designed to highlight morality. The contrast cited by Burton and Dunn is sharpened by Held (2006), who characterizes the ethic of care as containing features such as: (a) a commitment to meeting the needs of particular others; (b) an epistemological perspective that places value on others' emotions and relational capabilities which enable morally concerned persons in actual interpersonal contexts to understand what would be best; (c) a rejection of the notion that abstract theories provide a more effective starting point for reasoning about moral problems because they more likely avoid bias and arbitrariness (d) the adoption of a relational conception of persons, which is in stark contrast to Liberal individualism.

Burton and Dunn (1996) highlight the pioneering work of the American philosopher Nel Noddings whom they contend provided one of the first comprehensive theories of care. Noddings, they argue, saw relationships as ontologically basic to humanity. In this construction identity is defined by the set of relationships that individuals have with other humans. The most fundamental element of these relationships is the display of care, thus a caring relation is ethically basic to humans.

The notion that caring is basic to humans suggests that in the absence of care, humans are likely to function at a level below, or outside of, their better selves. To the extent that academic underperformance among students suggests that they are operating at a level below, or outside of, their better selves, one of the question that arises, which this paper seeks to examine, is whether the demonstration of care possesses the efficacy that could lead to improved academic performance. The related issue is whether in the absence of care, human behavior veers off its ideal or desired path and, in the case of students, towards indiscipline, that undermines performance. 
Sustainable Development. The World Commission on Environment and Development (WCED) in its 1987 publication, in relying on the seminal definition of sustainable development as articulated by the Brundtland Commission, restates that sustainable development is the ability to make development capable of meeting the needs of the present without compromising the ability of future generations to meet their own needs. The WCED notes that while the popular notions of sustainable development tended to focus on the environment, the application of the construct related to the equitable sharing of resources with the poor and other marginalized and vulnerable groups as well as ensuring stakeholder participation in decision-making. The WCED posits that while the concept of sustainable development has wide-ranging application, at its core is an approach to development that looks to balance different, and often competing, needs against an awareness of the environmental, social and economic limitations we face as a society.

According to the Organization for Economic Cooperation and Development (OECD) in a 2013 publication, reiterates the position of the WCED when it asserts that sustainable development requires:

(a) building strong coalitions to address issues of common concern and thus there is the need for more inclusive decision-making at all levels of society;

(b) establishing institutional mechanisms for interrogation of ideas and decisions at national and institutional levels which have economic, environmental, and social implications; and

(c) creating frameworks for stakeholder participation in policy making and implementation.

The field of sustainable development is a wide one covering dimensions, which may be broadly categorized into social and economic arrangements, conservation and management of resources, and relationships among various groups in communities and the wider society. The dimension which is the focus of this paper concerns relationships among groups in communities and the wider society. This dimension I wish to refer to as the 'third dimension' for ease of reference. Under this third dimension, the exploration is directed at relationships between teachers and students in the school community. Notwithstanding the focus on the third dimension, however, the other elements of sustainable development are considered in the discourse.

Discipline and Student Performance. Thompson et al. (2017) conducted a qualitative study of two formerly underperforming schools in Jamaica and found that two main factors were responsible for improvements in student discipline and academic performance. These factors were the quality of relationships (display of respect) that the principals sought to foster between themselves and teachers on the one hand, and fostering a culture of intolerance towards indiscipline at all levels.

Simba, Agak, and Kabuka (2016) conducted a study at 34 randomly selected schools in Kenya and found supportive evidence similar to that of Duckworth and Seligman (2006), who conducted a study among selected Grade 8 students in the USA, and Zhao and Kuo (2015) who conducted a study among selected 10th grade students in China. All three studies found that that discipline plays an important role in students' academic performance. The researchers concluded that self-discipline was a predictor of students' academic achievement. 
According to Canter and Canter (1997), one of the likely consequences of negative relations between teachers and students is student indiscipline. The opposite is equally true they contend, suggesting that one positive consequence of positive relations between teachers and students is that students are likely to comply more readily with the school's norms, and are more focused on academic and personal development.

There is a correlation between students' discipline and students' academic performance. Wishman and Hammer (2014) conducted a study analyzing over 160,000 student records and found that students with one or more discipline referrals were 2.4 times more likely to score below proficiency in math than those with no discipline referrals. The study further found that as the number of disciplinary referrals increased so did the odds of poor academic performance, such that students with 2 to 4 referrals were 2.7 more likely to score below proficiency, while students with 5 or more disciplinary referrals were 4.6 more likely to underperform in math. Karanja and Bowen (2012), and Rausch and Skiba (2005) made similar findings based on analyses of students' performance across a wide range of subjects and socio-economic contexts. They all concluded that there is a strong relationship between school discipline and general academic performance. The major ingredient in positive relationships between teacher and student is the students' perception of being respected (Zehm and Kotter, 1993; Thompson, 1998; Marzano, 2003; Boynton and Boynton, 2005). According to Zehm and Kottler (1993), students will never truly trust or open themselves up to hear what teachers have to say unless they sense that their teachers value and respect them. Similarly, Thompson (1998) suggests that the most effective tool that a teacher possesses in his or her efforts to foster a favorable learning climate is a positive relationship with our students.

Boynton and Boynton (2005) contend that improving students' relationships with teachers has important, positive and long-lasting implications for both students' academic and social development. Duke (1990), Boynton and Boynton (2005), and Rimm-Kaufman and Sandilos (2011) acknowledge that the existence of positive relationships between teachers and students will not by themselves result in academic gains. They do contend, however, that while the quality of the relationship between teachers and students will not by itself and in and of itself produce improved academic outcomes, students who have close, positive and supportive relationships with their teachers are more likely to attain higher levels of achievement than those students with more conflict in their relationships. If the desired outcomes of the teacher-student relationship as realized then students are likely to become more responsible and productive citizens who are better able to meet their socio-economic needs, while helping the society to meet the needs of others, and ultimately being less of a drain on the environment. Thus the attainment of the goals of schooling while dependent on the quality of relationships, which is both an issue of ethics of care and the third dimension of sustainable development has implications for the other dimensions of sustainable development.

Marzano (2003) is supportive of the arguments concerning the importance of quality relationships, pointing out, for example, that students' attitudes to rules and the consequences of not conforming to those rules will likely be one of indifference if the foundation of a good relationship is lacking. 
The sequence of impact factors, as outlined above, is striking. The quality of teacherstudent relationships influences the level of student discipline, and the level of student discipline affects the quality of academic performance as well as the degree of respect that students feel that their principals and teachers have for them. This interplay of factors suggests that there is likely to be a positive correlation between students' feeling of being respected and their attitude to school and to school authorities. These assertions are supported by the work of Knoell (2012) who conducted a study at two elementary schools, at opposite ends of the poverty spectrum, located in the Midwestern United States. The study was designed to determine the role of student-teacher relationships in the lives of fifth graders. Knoell found, among other things, that the things that students valued most included active listening, which is an act of showing respect.

Duke (1990) and Rimm-Kaufman and Sandilos (2011) further suggest that effective school discipline strategies must seek to encourage responsible behaviour and to provide all students with a satisfying school experience as well as to discourage misconduct. Thus in an atmosphere in which there are high levels of indiscipline the whole purpose of teaching and learning, and the very essence of schooling are defeated.

Theoretical Review. There is strong evidence that the underlying piece that holds the relationship between student and teacher together is respect (Ullman, 1997; Cohen, Cardillo \& Pickeral, 2011; Meador, 2016). Ullman conducted a case study of an urban high school English class, in a poor community with diverse nationalities and cultures, and found that by creating a culture of respect students were more encouraged to engage in academic activity. The consequences of greater engagement in academic activity have implications for sustainable development as has been shown above. Ullman, in her experiment, allowed students to share aspects of their culture and history, which were not included in the curriculum but which gave students an opportunity to share their stories and thus be better understood by members of the class. Agenda 21 is explicit in its affirmation that the nurturing of attitudes of tolerance and respect for other people's cultures is an important pillar in sustainable development. Ullman reports that the modality of her engagement with students was predicated on active listening to each student's story. The result of this was that the confidence of students grew and thus their performance improved. In addition to demonstrating her own commitment to listening, Ullman was successful in teaching her students the value of the discipline of listening. Thus not only did students respect her more but they also grew to respect each other.

Meador (2016) asserts that respecting students is essential for boosting teacher effectiveness. He laments the prevalence of cases of teachers berating and disrespecting students and condemns this practice as being unacceptable. He observes that teachers expect to be respected by students but note that many fail to realize that respect is a two-way street. Meador contends that all educators should show their students respect at all times including tense moments of conflict.

Cohen et al., (2011) argue that improving school climate means measuring the level of respect and then using that information to improve the quality of school life. They suggest that respect means being taken seriously and that when a person acts respectfully he or she reflects appreciative feelings for another person or group. Cohen et al., emphasize what respect means noting that it involves actually listening to students, showing regard for their feelings and taking 
steps to make them part of the school by engaging them in helping to solve some of the problems facing the school.

Idu and Ojedapo (2011) noted that Rogers (2003) observed that if teachers ignore students' problems and complaints whether academic or otherwise this prepares ground for indiscipline to the students. The act of ignoring is a form of lack of respect (Cohen et al., 2011). Both Valenzuela (1999) and Mendler (2001) agree that students want to be listened to and respected as human beings with wants, desires, fears, and emotions.

Empirical studies consistent with notions of the impact of teacher-pupil relationships on learning, behaviour and attendance have been conducted by Sakiz \&Woolfolk-Hoy (2009) and Gorard \& See (2011). These studies have shown that poor student-teacher relationships are often characteristic of those students with problems in school. Hattie (2009) conducted a metaanalysis of 50,000 studies, including studies reporting direct student appraisals of their teachers, and found strong support for the notion that quality teachers had high expectations of their students and demonstrated care for them. The communication of high expectations is an important climate-defining characteristic.

The existence of a strong supportive relationship between teacher and student (relatedness) is critical for students' comfort with the learning environment and an important medium of that support is engaged listening (Ullman, 1997). In this regard the work of Hughes and Kwok (2007) is instructive. They conducted a study in Texas, which sought in part to examine the influence of student-teacher relationships on student achievement in the primary grades. The study involved 443 ethnically diverse $1^{\text {st }}$ graders, of which were $52.6 \%$ males and $47.4 \%$ females. The study found that the quality of teachers' relationships with students (served to correct and counterbalance the traditional adverse effects that normally arise in relation to children's background and classroom engagement. The study further found that the quality of child classroom engagement served to inform the quality of student-teacher relatedness and child achievement the following year.

A further feature of the research of Hughes and Kwok was striking. The study found that the improved student-teacher and parent-teacher relationships were stronger among African American children and their parents, relative to Hispanic and Caucasian children and their parents. This difference was significant given that African American students had generally less supportive relationships with teachers. In effect what the study showed was that the need for relatedness being greater among African Americans had a greater impact on their academic achievement. It is therefore not surprising that Barrow (2015), drawing on insights from a qualitative study at the college level, would conclude that caring relations with students was effective in supporting students' needs and ultimately success.

Commenting on the findings of their research, Hughes and Kwok (2007) note that students' sense of social relatedness at school is a key construct in contemporary theories of academic motivation and engagement, citing Connell and Wellborn (1991) and Eccles, Wigfield, and Schiefele (1998) among others. Hughes and Kwok concluded, that when students experience a sense of belonging at school and supportive relationships with teachers and classmates, they are motivated to participate actively and appropriately in the life of the 
classroom, and that when deep relatedness is established in the early grades it supports academic motivation and achievement over the long term as cited by Hughes and Kwok (2007).

The conclusion that may be drawn is that lack of, or weak relatedness between teachers and students will likely expose students to minimal engagement and under-achievement and this places students at risk of falling into indiscipline.

The importance of relatedness in managing discipline in schools is supported by RimmKaufman and Sandilos (2011). In a compelling article entitled "Improving Students' Relationships with Teachers to Provide Essential Supports for Learning" the authors argued that improving students' relationships with teachers has important, positive and long-lasting implications for both students' academic and social development. They concede that the existence of positive relationships between teachers and students will not by itself result in academic gains, but that those students who benefit from close, positive and supportive relationships with their teachers will attain higher levels of achievement than those students with more conflict in their relationships.

It may therefore be concluded based on the submissions of Hughes and Kwok (2007); Connell and Wellborn (1991); Eccles et al., (1998); and Rimm-Kaufman and Sandilos (2011), that for a relationship to be regarded mutually as positive and warm means that the parties to the relationship feel respected. Students who feel respected by their teachers are more easily swayed by their teachers to refrain from acts of indiscipline. In effect teachers have greater influence over students who feel that they are respected by their teachers.

Rimm-Kaufman and Sandilos express it beautifully arguing that a student who feels a strong personal connection to his or her teacher and who talks with his or her teacher frequently and in the process receives more constructive guidance and praise rather than just criticism from his or her teacher, is likely to trust the teacher more and thus show more engagement in learning. By extension more engagement in learning will mean less interest in, and time for, inappropriate conduct and the likely result will be higher levels of academic achievement. While emphasizing that the content of learning must be attractive in order to inspire interest on the part of students, Rimm-Kaufman and Sandilos reiterate that positive teacher-student relationships draw students into the process of learning and promote their desire to learn.

Down, Lambert, and McPherson-Kerr (2006) examined a "Change from Within" project. The project involved seven schools that are located in volatile inner city communities of Kingston, Jamaica and had high incidence of violence. The project was designed to enable the stakeholders acquire a better understanding of the problem of violence and its impact on their communities and on them individually. Three sets of findings stood out as causes of violence as reported by the authors. The first was that notions of disrespect ranked highly as both catalysts and manifestations of violence. This notion of being disrespected as a cause of violence (which is expressed in Jamaican parlance as 'dissed') was not limited to student to student, but also teacher to student. A second set of critical findings relate to students' sense of the care that they receive as members of the community. That is, the authors found that students' sense of the absence of care was a contributor to violence. The third area of note was that students were of the view that a contributor to violence was teachers' perceived apathy, tardiness, and lack of commitment 
towards issues of violence in the classroom that affected students. Students also reported that lack of commitment and indifference on the part of teachers negatively affected the teaching and learning process.

The main objective of the "Change from Within" project, which was started in 1992, was to enable schools overcome by violence to improve relationships, having come to understand cause and impact. The findings of Down, Lambert, and McPherson-Kerr (2006) show that the issues of students' perception being respected and cared for play a critical role in their capacity to relate to others. The capacity to relate to others in a non-violent manner has major implications for the survival, and therefore the sustainability, of communities. The relationship between students' perceptions of being respected and feelings of being cared for, on the one hand, and the apparent value they place on teachers' interest, enthusiasm and commitment, on the other, highlight the importance of listening as a key variable in mutually respectful student teacher relationships.

\section{Methodology}

Data used in this study were drawn from primary and secondary sources and were gathered in various years ending in 2017 with the latest set of data dated 2015. The primary data for were drawn from a study that used a sample of 160 Grades 10 and 11 students. Nine of the questionnaires were spoilt thus the analysis of the data was based on a total of 151 responses. The study was undertaken to determine students' perceptions and expectations of their principals and teachers. The study was conducted using a self-designed instrument as shown at Appendix A. The focus of the instrument was on issues such as listening, qualities of leadership, teachers' openness to correction, and involvement in decision-making, the extent to which teachers sought to make learning exciting, and the regard that teachers have for the views of students.

Instrument and Description of Sample. The instrument used to collect the primary data was pilot tested twice as well as reviewed by a three-person panel. The instrument met content validity measures evidenced by the strengths of the correlations that were found among several variables, as well as possessed strong internal consistency with a C-Alpha .938. The instrument was administered in four locations with the assistance of teachers from each school. In two schools the teachers arranged to have randomly chosen students complete the instruments during a designated period of a school day and at the other two schools the teachers gave the students the instruments and invited them to complete and return by the end of a school day. Both the sample size and its representativeness support the generalizability of the findings. Two of the schools were located in rural Jamaica and the other two in the capital city, Kingston; two schools were unisex and two co-ed. The data were analyzed using SPSS Version 17.

\section{Results}

Research Question \# 1 - Students' Assessments of Principals' and Teachers' Demonstration of Respect and the Influence of Assessments on Respect for Teachers and Principals. The study found five strong positive correlations among five sets of variables that explored the perspectives of students in relation to their principals and three moderate strength correlations in relation to students' perspectives on teachers as shown in Table 1. Pearson's 
correlations were used, as opposed to Spearman's, to assess the relationships given that continuous variables are thus are more effectively measured using Pearson's.

Table 1. Correlations between Listening and Respect

\begin{tabular}{|c|c|c|c|}
\hline Item \# & Variable 1 & Variable 2 & Correlation Strength \\
\hline 1 & My principal is a good listener & My principal respects students & .749 \\
\hline 2 & Students respect the principal & $\begin{array}{l}\text { My principal is a good } \\
\text { listener }\end{array}$ & .693 \\
\hline 3 & Students respect principal & Principal respects students & .776 \\
\hline 4 & $\begin{array}{l}\text { My principal shows interest in } \\
\text { students' concerns }\end{array}$ & I respect my principal & .680 \\
\hline 5 & My principal is a good listener & $\begin{array}{l}\text { My principal shows interest in } \\
\text { students' concerns }\end{array}$ & .691 \\
\hline 6 & Students respect teacher & Teacher is a good listener & .365 \\
\hline 7 & My teacher is a good listener & I feel respected by my teacher & .388 \\
\hline 8 & My teacher is a good listener & $\begin{array}{l}\text { My teacher encourages my } \\
\text { self-confidence }\end{array}$ & .392 \\
\hline
\end{tabular}

In addition of the foregoing correlations, the variable 'respect' accounted for $21.489 \%$ of the variation in the data. The sub-factors listed in Table 1 were among the sub-factors that comprised the variable respect.

Research Question \# 2 - Relationship between Students' Assessment of Principals' and Teachers' Demonstration of Respect and Students' Views on the Quality of the Schools Leadership and Learning Environment. The study found that $63.6 \%$ of the 151 respondents either agreed or strongly agreed that the expression of concern shown to them by their principals influences the respect they have for their principal. The feeling of respect for leaders in an organization is a definitive climate setting factor and reflection of the assessment of the quality of leadership.

In addition to the fact that almost two-thirds of the sample felt that expressions of concern led to feelings of respect, the study found the correlations outlined in Table 2 . These correlations also define the character of the school environment as perceived by students. 
Table 2. Correlations between Students' Attitudes and Principals' Teachers' Behaviours

\begin{tabular}{|c|c|c|c|}
\hline Item \# & Variable 1 & Variable 2 & Correlation Strength \\
\hline$\overline{1}$ & $\begin{array}{l}\text { My principal shows concerns for } \\
\text { underperforming students }\end{array}$ & $\begin{array}{l}\text { My principal is a good role } \\
\text { model }\end{array}$ & .682 \\
\hline 2 & My teacher is a good role model & My teacher is a good listener & .440 \\
\hline 3 & My teacher is a good role model & $\begin{array}{l}\text { I have a good relationship } \\
\text { with my teacher }\end{array}$ & .526 \\
\hline 4 & I respect my teacher & I feel respected by my teacher & .446 \\
\hline 5 & I respect my teacher & My teacher accepts correction & 386 \\
\hline 6 & $\begin{array}{l}\text { My teacher makes teaching } \\
\text { exciting }\end{array}$ & I respect my teacher & .321 \\
\hline 7 & $\begin{array}{l}\text { My teacher makes teaching } \\
\text { exciting }\end{array}$ & I feel my teacher respects me & .387 \\
\hline
\end{tabular}

The variable 'modeling' accounted for 38\% of the variation in the data of which the first five pairs of sub-factors were contributors.

Research Question \# 3: Relationship between Gender, School type and School Location and Students' Assessments. Males were generally less of the view that their leaders showed interest in their concern, and thus, by extension, listened to them. Thirty-four (34) of the sixty-seven (67) males approximately 50\% were either unsure about, or disagreed, or strongly disagreed that their principal showed interest in students' concern. By comparison, 25\% of females were either unsure or disagreed that their principal showed interest in students' concerns. There were no strong disagreements among girls in relation to this question. Using the variable of location the study found that a mere $53 \%$ of students in rural areas believe that their principals show interest in their concerns. On the other hand $68 \%$ of students at urban schools hold the view that their principals show interest in their concerns. The variable of school type disclose major contrasts wherein a mere $35 \%$ of students at traditional schools express the view that their principals show interest in their concerns with $17 \%$ being unsure and $41 \%$ disagreeing or strongly disagreeing. A very different picture is found with non-traditional schools with $93 \%$ agreeing or strongly agreeing that their principals show interest in their concerns and a mere 5\% disagreeing or strongly disagreeing. Five per cent said they were unsure.

A stark picture was found in relation to students' respect for principal, wherein $92 \%$ of females say they respect their principals compared to $68 \%$ of males. When the variable of location is examined it was found that $92 \%$ of students from urban areas say they respect their principals; this compares to $72 \%$ of students from rural areas that are of the same view. The school type variable showed that $95 \%$ of students at non-traditional schools say they respect their principals compared to $68 \%$ of students at traditional schools.

Research Question \# 4: Support in the Literature for the Relationship between Respect and Ethics of Care and Sustainable Development. The final research question sought to explore whether there is support in the scientific literature for characterizing teachers' and 
principals' display of respect as being related to the ethics of care and sustainable development. The scientific literature is unequivocal that respect is an important and indispensible component of the ethics of care and that the most vital expression of the ethics of care is the show of respect. It is perhaps even trite logic to argue that the act of caring and the ethics of care require, as a foundation, the act of showing respect. The scientific literature is replete with findings that support the existence of a relationship between students' perceptions of being listened to, and their feelings of being respected. Among the authorities who have found such a relationship are Burton and Dunn (1996), Rimm-Kaufman and Sandilos (2011), Held (2006), Down et al., (2006), Eccles et al., (1998), and Ullman (1997).

\section{Discussion}

The element of respect is a critical requirement of caring teacher-student relationships as well as sustainable and productive student to student relationships (Down et al., 2006; Held, 2006; Burton \& Dunn, 1996). When students perceive that they are respected by their teachers there are positive consequences for the quality of teacher-student relationships (Zehm \& Kotter, 1993; Thompson, 1998; Marzano, 2003). A foundational respect-producing behavior in teacherstudent relationships is listening according to Kohn (1996) and Boynton and Boynton (2005).

The foregoing positions are consistent with the findings of this paper which has found that respectful and caring teacher-student and student-student relationships also result in improved academic performance and discipline (Ullman, 1997; Marzano, 2003; Duckworth and Seligman, 2006; Rimm-Kaufman and Sandilos, 2011; Zhao and Kuo, 2015; Simba et al., 2016).

Respect thus begets respect as Meador (2016) affirms and mutually respectful engagements between teacher and student will result in facilitation of involvement in decisionmaking, which is an expression of 'hearing from the other' as well as responsiveness to correction which is a form of deference shown to the views of the other. This practice of involving others in decision-making is major pillar of sustainable according to the OECD (2013).

This research has, however, uncovered some imbalances in the practices of decisionmaking, and attention to the concern of some students when perceptions are examined from perspectives of gender, school location, and school type. That five times as many boys than girls disagreed or strongly disagreed that their principal showed concern for them was 39\% versus $9 \%$ provides an interpretive perspective on the comparatively higher levels of indiscipline among boys compared to girls. It is perhaps noteworthy that there were no strong disagreements among girls. Similarly that $92 \%$ of females say they respect their principals compared to $68 \%$ of males probably points to the need for improved relationships between males and their principals.

It also appears to be that case that relationships between teachers and students in rural areas are less respectful than those in urban areas given that $92 \%$ of students from urban areas say they respect their principals compared to $72 \%$ of students from rural areas. By contrast students at non-traditional schools seem to enjoy better relationships with their teachers with $95 \%$ of students at non-traditional high schools saying they respect their principals compared to $68 \%$ of students at traditional high schools. 


\section{Conclusions and Recommendations}

The findings of this study show that showing respect is a central or dominant element of the ethics of care and a vital contributor to sustainable teacher-student and student-student relationships. The quality of such relationships has implications for both students' discipline and academic performance. The act of showing respect, and the expectations students have of it, inform the degree of respect that students have for their principals and teachers. Students' expectations of what respect involves includes their being allowed to participate in some decision-making processes, attention being shown to their concerns, and care being extended to students who are underperforming.

The facilitation of involvement in decision-making, attention to others' concerns (particularly when those others have less organizational power) and reaching out to vulnerable or at-risk members of the community are actions which are not only likely to result in improved cooperation and performance but increase the probability of sustainable development. The increased probability of sustainable development is predicated on the fact that decisions will more likely reflect the will and wish of the majority.

In light of the foregoing the following recommendations are made for the consideration of policy makers, institutions that are involved in the training of principals and teachers, as well as practitioners and researchers.

(1) Having regard to the established relationship between listening and respect, the curriculum for the training of teachers and continuing professional development of teachers and principals should include practice and simulation exercises on effective listening.

(2) Given the established relationship between the quality of relationships, generally, and teacher-student relationships specifically, on the one hand, and sustainable development, on the other, it is recommended that teacher training programmes include courses and other competence-building activities related to sustainable development.

(3) Having regard to some of the pragmatic elements and implications of showing respect, and given the relationship between listening, on the one hand, and respect and sustainable development, respectively - on the other hand, it is recommended that schools be mandated to put in place or review internal structures for student participation in decision-making and the facilitation of student feedback on the processes of management of the school.

(4) Given the disparity between boys and girls assessment of the quality of their relationships with teachers and principals, wherein boys report feeling lower levels of inclusion; policy makers, trainers, and practitioners are encouraged to explore new strategies that give greater space to giving boys a voice.

(5) Given the disparities between how students at rural versus urban, and traditional versus non-traditional high schools relate their experience of respect and related constructs, further study is required to examine what factors may account for these disparities. 


\section{References}

Barrow, R. (2015). Giving teaching back to teachers: A critical introduction to curriculum theory. United Kingdom: Routledge.

Boynton, M., \& Boynton, C. (2005). The educator's guide to preventing and solving discipline problems. Virginia: ASCD.

Burton, B. K., \& Dunn, C. P. (1996). Feminist ethics as moral grounding for stakeholder theory. Business ethics quarterly, 6(02), 133-147.

Cohen, J., Cardillo, R., \& Pickeral, T. (2011). Creating a climate of respect: Promoting respectful schools. Educational Leadership. 69(1). Retrieved from http://www.ascd.org /publications/educational-leadership/sept11/vol69/num01/Creating-a-Climate-ofRespect.aspx

Connell, J. P., \& Wellborn, J. G. (1991). Competence autonomy and relatedness: A motivational analysis of self-system processes. In R. Gunnar \& L. A. Sroufe (Eds.), Self-processes in development: Minnesota Symposium on Child Psychology, Vol 23 (pp. 43-77). Chicago: Chicago University Press.

Covey, S. (2000). The 7 habits of highly effective people. New York: Free Press.

Dillon, R. S. (2015). Respect. The Stanford Encyclopedia of Philosophy (Fall 2015 Edition). Retrieved from http://plato.stanford.edu/archives/fall2015/entries/respect/

Down, L., Lambert, C., \& McPherson-Kerr, C. (2006). Violence in Jamaican schools and the implications for teacher education. In R. Davies \& L. Down (Eds.), Broadening the Vision for Teacher Education in the Caribbean (pp 139-160). UWI, Mona: Institute of Education Publication Series Vol. 2.

Duckworth, A. L., \& Seligman, M. E. (2006). Self-discipline gives girls the edge: Gender in selfdiscipline, grades, and achievement test scores. Journal of educational psychology, 98(1), 198.

Duke, D. L. (1990). Setting goals for professional development. Educational Leadership, 47(8), $71-75$.

Dunkley, A. (2013, May). School violence focus. Jamaica Observer. Retrieved from http://www.jamaicaobserver.com/news/School-violence-focus----Education-ministry-toimplement-measures-starting-summer

Eccles, J. S., Wigfield, A., \& Schiefele, U., (1998). Motivation to succeed. In W. Damon (Series Ed.) \& N. Eisenberg (Vol. Ed.), Handbook of child psychology (5th ed., Vol. III, pp. 1017015-1095). New York: Wiley. 
Gilligan, C. (1982). In a different voice. Cambridge: Harvard University Press.

Gorard, S., \& See, B. H. (2011). How can we enhance enjoyment of secondary school? The student view. British Educational Research Journal, 37(4), 671-690.

Hamre, B. K., \& Pianta, R. C. (2001). Early teacher-child relationships and the trajectory of children's school outcomes through eighth grade. Child development, 72(2), 625-638.

Hattie, J. A. C. (2009). Visible learning: A synthesis of 800+ meta-analyses on an achievement. Abingdon: Routledge.

Held, D. (2006). Models of democracy. Polity and Stanford University Press.

Howarth, R. B. (2012). Sustainability, well-being, and economic growth. Minding Nature, 5(2), 32-39.

Hughes, J., \& Kwok, O. M. (2007). Influence of student-teacher and parent-teacher relationships on lower achieving readers' engagement and achievement in the primary grades. Journal of educational psychology, 99(1), 39.

Idu, A. P., \& Ojedapo, D. O. (2011). Indiscipline in secondary schools: A cry to all stakeholders in education. Journal of Educational and Social Research, 81.

Karanja, R., \& Bowen, M. (2012). Student indiscipline and academic performance in public secondary schools in Kenya. Daystar University Centre for Research and Publications Working Paper Series. Retrieved from www.daystar.ac.ke /index.php?option=comrokdownloads

Knoell, C. (2012). The role of the student-teacher relationship in the lives of fifth graders: A mixed methods analysis. Nebraska: University of Nebraska.

Kohn, A. (1996). Beyond discipline: From compliance to community. Virginia: ASCD.

Leithwood, K., Louis, S., Anderson, S., \& Wahlstrom, K. (2004). How leadership influences student learning. New York: The Wallace Foundation.

Macaulay S. (2010). Are you a good role model? Think: Cranfield.

Marzano, R. J. (2003). What works in schools: Translating research into action. Virginia: ASCD.

Meador, D. (2016). Respecting students is essential for boosting effectiveness Retrieved from http://teaching.about.com/od/Information-For-Teachers/fl/FrequentTeacher-Mistakes-that-Can-be-Avoided.htm

Mendler, A. N., (2001). Connecting with students. Virginia: ASCD. 
Ministry of Education Statistics, (2015, May). Child month fact-Suspensions and expulsions: A cause for concern. Retrieved from http://digjamaica.com/blog/2015/05/26/child-monthfact-suspensions-and-expulsions-a-cause-for-concern/

National Education Inspectorate. (2015). Report. Retrieved from http://www.nei.org.jm/Portals /0/Chief\%20Inspector's\%20Baseline\%20Report\%202015.pdf?ver=2015-09-30-125548787

Noddings, N. (1984) Caring: A feminine approach to ethics and moral education. Berkeley: University of California Press.

OECD. (2013). Education policy outlook: Finland. OECD Publishing: Paris. http://www.oecd.org/edu/EDUCATION\%20POLICY\%20OUTLOOK\%20FINLAND_E N.pdf

Rausch, M. K., \& Skiba, R. J. (2005). The academic cost of discipline: The contribution of school discipline to achievement. Montreal: In annual meeting of the American Educational Research Association

Rimm-Kaufman, S., \& Sandilos, L. (2011). Improving students' relationships with teachers to provide essential supports for learning. Teacher's Modules.

Rogers, B. (2003). Effective supply teaching: Behaviour management, classroom discipline and colleague support. SAGE.

Sakiz, G., \& Woolfolk-Hoy, A. (2009). Improving middle school students' academic enjoyment, academic self-efficacy, and academic effort in mathematics: Teacher affective support effect. Paper presented at the annual meeting of the European Conference on Educational Research, Vienna, Austria.

Simba, N. O., Agak, J. O., \& Kabuka, E. K. (2016). Impact of Discipline on Academic Performance of Pupils in Public Primary Schools in Muhoroni Sub-County, Kenya. Journal of Education and Practice, 7(6), 164-173.

Starratt, R. J. (2005). Building an ethical school: A practical response to the moral crisis in schools. United Kingston: Routledge.

Thompson, C.S. (2009). Leadership and indiscipline in schools. Gleaner January 25. Retrieved from http://jamaica-gleaner.mobi/20090125/cleisure/cleisure6.php

Thompson, C.S. (2009). Towards Solutions: Fundamentals of transformational leadership in a postmodern era. Mandeville: Northern Caribbean University Press.

Thompson, C.S. (2015). Locating the epicenter of effective (educational) leadership in the $21^{\text {st }}$ century. Kingston: Caribbean Leadership Re-Imagination Initiative. 
Thompson, C., Burke, T., King, K., \& Wong, S. (2017). Leadership strategies for turning around underperforming schools: An examination of the experiences of two schools in Jamaica. Journal of Education and Development in the Caribbean, 16 (2).

Ullman, J. L. (1997). A case study of an urban high school English class: Encouraging academic engagement by creating a culture of respect. Retrieved from http://wwwlib.umi .comdissertations/fullcit/9813680

Valenzuela, A. (1999). Subtractive schooling: Issues of caring in education of US-Mexican youth. New York: State University of New York Press.

Whisman, A., \& Hammer, P. C. (2014). The association between school discipline and mathematics performance: A case for positive discipline approaches. Charleston, WV: West Virginia Department of Education, Office of Research.

Wood, A. W. (1999). Kant's ethical thought. United Kingdom: Cambridge University Press.

World Commission on Environment and Development (WCED). (1987). Our common future. New York: Oxford University Press.

Zehm, S. J., \& Kotter, J. A. (1993). On being a teacher: The human dimension. California: Corwin Press Inc.

Zhao, R., \& Kuo, Y. (2015). The role of self-discipline in predicting achievement for $10^{\text {th }}$ graders. International Journal of Intelligent Technologies and Applied Statistics, 8(1), 61-70, DOI: 10.6148/IJITAS.

\section{Author Biography}

Dr. Canute Thompson is Lecturer in the School of Education, Mona Campus of The University of the West Indies. He is a co-founder of the Caribbean Leadership Re-Imagination Initiative. His publications include: Locating the Epicentre of Effective (Educational) Leadership in the $21^{\text {st }}$ Century (2015) and Leadership Re-Imagination: A Primer of Principles and Practices (2013.) canutethompson1@gmail.com or canute.thompson02@uwimona.edu.jm 